\title{
Short Report: Changes in Knowledge of Bat Rabies and Human Exposure among United States Cavers
}

\author{
Jason M. Mehal,* Robert C. Holman, Danny A. Brass, Jesse D. Blanton, and Brett W. Petersen \\ Centers for Disease Control and Prevention (CDC), Atlanta, Georgia; National Speleological Society, New Haven, Connecticut; \\ Epidemic Intelligence Service, CDC, Atlanta, Georgia
}

\begin{abstract}
The purpose of the study was to evaluate changes in the knowledge of bat rabies and human exposure among United States cavers during the last decade. A survey was distributed among cavers who attended the National Speleological Society convention in 2000 and those who attended in 2010. In 2000 and 2010, 392 and 108 cavers, respectively, responded to the questionnaire. Eighty-five per cent of respondents in 2000 indicated a bat bite as a risk for rabies compared with all respondents in $2010(P<0.0001$ controlling for age). The proportion of respondents indicating that they were advised to receive rabies pre-exposure prophylaxis (PreEP) because of caving increased (17\% and 29\%; $P=0.03$ controlling for age). Among these, PreEP was received by $56 \%$ and $45 \%$. Although recognition of the risk of rabies exposure from bats is important, the proportion of cavers acting on current recommendations regarding PreEP does not appear to have improved in the past decade.
\end{abstract}

\section{INTRODUCTION}

During the last century, the number of human rabies cases in the United States has dramatically decreased, particularly as a result of vaccination of domestic animals and wildlife, education of the public and health professionals, and successful administration of post-exposure prophylaxis. ${ }^{1}$ Despite this progress, human rabies cases persist, particularly those resulting from exposure to bats. ${ }^{1,2}$ During 2002-2011, 88\% $(N=21)$ of all domestically acquired human rabies cases were caused by bat rabies variants. ${ }^{1}$ Because of the potential for exposure to possibly rabid bats associated with caving, it is currently recommended by the Advisory Committee on Immunization Practices that cavers receive pre-exposure prophylaxis $(\text { PreEP })^{2}$; however, many cavers do not agree with or adhere to these recommendations. ${ }^{3}$ This study aims to evaluate changes in the knowledge of bat rabies and human exposure among United States cavers during the last decade.

\section{METHODS}

A survey was distributed among cavers attending the National Speleological Society (NSS) Convention in Essex Junction, Vermont in August 2010. The NSS has approximately 10,000 members, which may approximate the number of active United States cavers. ${ }^{4}$ A copy of the survey was included in the registration packet given to all attendees. The survey assessed demographic information, knowledge of bat rabies, and potential for human exposure. Categorical characteristics were compared between groups using the $\chi^{2}$ test or the Fisher's exact test (2-sided) as appropriate; to control for age, logistic regression was conducted using the age groups $<40$, $40-49,50-59$, and $\geq 60$ years. ${ }^{5}$ Continuous characteristics were compared between groups using the Wilcoxon rank-sum test. ${ }^{6}$ Comparisons were also made between corresponding characteristics of the current 2010 survey and a prior survey administered at the 2000 NSS Convention in Elkins, West Virginia. ${ }^{3}$

* Address correspondence to Jason M. Mehal, Centers for Disease Control and Prevention (CDC), 1600 Clifton Road NE MS-A30, Atlanta, GA 30333. E-mail: jmehal@cdc.gov

\section{RESULTS}

Questionnaires were returned from 108 (15\%) of 709 individuals attending the 2010 convention. Respondents had a median age of 58 years (interquartile range [IQR]: 49-64), were predominantly male $(67 \%)$, and $88 \%$ had at least a college degree (Table 1). The median number of years caving among respondents was 35 (IQR: 23-44). The majority (64\%) of respondents indicated seeing bats about half the time or more $(>40 \%)$ that they go caving; 5\% indicated having ever been bitten or scratched by a bat while caving. Twenty-nine per cent of respondents had been advised to get rabies PreEP because of their caving activities; however, only $15 \%$ had received PreEP (Table 1). Those advised to get PreEP were more likely to have received it than those who were not advised (45\% and 3\%, respectively; $P<0.0001$ controlling for age). Although $95 \%$ of respondents considered rabies a very severe disease, only $6 \%$ of respondents considered caving to be an activity that warrants rabies PreEP.

Respondents were asked to indicate which type(s) of bat contact they considered as a risk for getting rabies. All respondents acknowledged a bat bite as a rabies exposure risk, and $69 \%$ believed a bat scratch was a risk for rabies exposure. About one-fourth indicated touching bat guano, urine, or blood $(26 \%)$ or contact with a dead bat $(25 \%)$ as risks for rabies exposure. Few respondents identified touching with exposed skin $(13 \%)$, being around bats that never touch you $(6 \%)$, or contact with a flying bat $(5 \%)$ as a risk for rabies exposure.

Responses from the 2010 survey were compared with those from a similar survey given at the 2000 NSS Convention (Table 1). ${ }^{3}$ Compared with respondents in the 2000 survey, participants in this survey were older, had been caving longer, and were more likely to have a college degree; the proportion of male respondents was similar for both surveys (Table 1). Although the proportion of respondents advised to receive PreEP increased from 2000 to 2010 (17\% and 29\%, respectively; $P=0.02$ controlling for age), the proportion who had received PreEP remained similar $(19 \%$ and $15 \% ; P=0.16$ controlling for age). Respondents in this study more commonly identified a bat bite as a risk for rabies $(85 \%$ versus $100 \% ; P<0.0001$ controlling for age). 
TABLE 1

Comparison between characteristics from surveys distributed to cavers at the National Speleological Society Conventions in 2000 and 2010 , United States*

\begin{tabular}{|c|c|c|c|c|}
\hline Characteristic & 2000 Survey no. $(\%)$ & 2010 Survey no. $(\%)$ & $P$ value $\dagger$ & $\begin{array}{l}P \text { value controlling } \\
\text { for age } \neq\end{array}$ \\
\hline Total & 392 & 108 & & \\
\hline Male gender & $266 / 389(68)$ & $72 / 108(67)$ & 0.74 & - \\
\hline College degree & $295 / 388(76)$ & $94 / 107(88)$ & 0.01 & 0.01 \\
\hline Advised to get PreEP because of caving & $66 / 391(17)$ & $31 / 108(29)$ & 0.01 & 0.03 \\
\hline Received PreEP among those advised to get PreEP & $37 / 65(57)$ & $14 / 31(45)$ & 0.28 & 0.06 \\
\hline Received PreEP & $76 / 391(19)$ & $16 / 108(15)$ & 0.27 & 0.15 \\
\hline Had a rabies titer checked among those who received PreEP & $36 / 76(47)$ & $6 / 16(38)$ & 0.47 & 0.15 \\
\hline Had a rabies titer checked & $45 / 390(12)$ & $6 / 108(6)$ & 0.07 & 0.01 \\
\hline \multicolumn{5}{|l|}{ Consider scenario as a risk for rabies } \\
\hline Bat bite & $333 / 390(85)$ & 107/107 (100) & $<0.0001$ & $<0.0001$ \\
\hline Bat scratch & $233 / 385(61)$ & $74 / 107(69)$ & 0.10 & 0.42 \\
\hline Being around bats that never touch you & $45 / 389(12)$ & $6 / 107(6)$ & 0.08 & 0.01 \\
\hline \multirow[t]{2}{*}{ Contact with a flying bat } & $51 / 388(13)$ & 5/107 (5) & 0.02 & 0.01 \\
\hline & Median $(I Q R)$ & Median $(I Q R)$ & & \\
\hline Age (years) & $48(39-54)$ & $58(49-64)$ & $<0.0001$ & - \\
\hline Years caving & $22(11-32)$ & $35(23-44)$ & $<0.0001$ & $<0.0001$ \\
\hline
\end{tabular}

\section{DISCUSSION}

Although respondents acknowledged the severity of rabies and the risk of transmission through bat bites and scratches, only $6 \%$ believed caving to be an activity that warrants PreEP, and $15 \%$ had received PreEP. Low perceived risk of exposure to rabies, particularly unrecognized exposure, may have influenced individuals not to seek PreEP., ${ }^{7,8}$ Other barriers to PreEP may include a limited knowledge of rabies, high cost of vaccination, and fear of adverse vaccine reaction. 8 The proportion of respondents advised to receive PreEP increased from 2000 to 2010; however, the proportion who had received PreEP remained similar.

Several limitations of this study should be considered. The low response rate and incomplete responses to the 2010 survey may have limited the ability to detect associations between characteristics. Additionally, the survey may have been subject to response bias and/or selection bias. Respondents to the survey may not have been representative of all cavers or those attending the NSS Convention. Comparisons between the present and earlier survey responses may have been affected by underlying differences in the respondent groups. ${ }^{3}$

The proportion of cavers acting on current recommendations regarding PreEP does not appear to have increased in the past decade; however, greater compliance may be achieved by increasing awareness of the recommendation, as nearly half of those advised to receive PreEP had done so. Additional messaging should be developed for this population to ensure appropriate risk assessments and recommendations for PreEP are considered for their recreational or occupational caving activities.

Received August 29, 2013. Accepted for publication October 19, 2013. Published online December 2, 2013.

Acknowledgments: We thank Charles Rupprecht and Allison Dusick for technical support. We also thank the survey participants at the 2010 National Speleological Society Convention.
Disclaimer: The findings and conclusions in this report are those of the authors and do not necessarily represent the official position of the Centers for Disease Control and Prevention (CDC).

Authors' addresses: Jason M. Mehal, Robert C. Holman, Jesse D. Blanton, and Brett W. Petersen, Division of High-Consequence Pathogens and Pathology (DHCPP), National Center for Emerging and Zoonotic Infectious Diseases (NCEZID), Centers for Disease Control and Prevention (CDC), Atlanta, GA, E-mails: jmehal@cdc .gov, rholman@cdc.gov, asi5@cdc.gov, and ige3@cdc.gov. Danny A. Brass, National Speleological Society, New Haven, CT, E-mail: brassda@yahoo.com.

\section{REFERENCES}

1. Blanton JD, Dyer J, McBrayer J, Rupprecht CE, 2012. Rabies surveillance in the United States during 2011. J Am Vet Med Assoc 241: 712-722.

2. Manning SE, Rupprecht CE, Fishbein D, Hanlon CA, Lumlertdacha B, Guerra M, Meltzer M, Dhankhar P, Vaidya S, Jenkins S, Sun B, Hull H, 2008. Human rabies preventionUnited States, 2008: recommendations of the Advisory Committee on Immunization Practices. MMWR Recomm Rep 57: 1-28.

3. Gibbons RV, Holman RC, Mosberg SR, Rupprecht CE, 2002. Knowledge of bat rabies and human exposure among United States cavers. Emerg Infect Dis 8: 532-534.

4. Smallwood K, 2013. NSS News 2013 Members Manual. The National Speleological Society, April Part 2. Huntsville, AL.

5. Kleinbaum DG, Klein M, 2002. Logistic Regression: A Self-Learning Text. Second edition. New York: Springer-Verlag.

6. Lehmann E, 1975. Nonparametrics: Statistical Methods Based on Ranks. New York, NY: Wiley.

7. Brass DA, 2009. Rabies vaccine strategies: concepts of rabies prophylaxis for the caving community. PRS 109: 6-16.

8. Altmann M, Parola P, Delmont J, Brouqui P, Gautret P, 2009. Knowledge, attitudes, and practices of French travelers from Marseille regarding rabies risk and prevention. J Travel Med 16: $107-111$.

9. Piyaphanee W, Kittitrakul C, Lawpoolsri S, Gautret P, Kashino W, Tangkanakul W, Charoenpong P, Ponam T, Sibunruang S, Phumratanaprapin W, Tantawichien T, 2012. Risk of potentially rabid animal exposure among foreign travelers in Southeast Asia. PLoS Negl Trop Dis 6: e1852. 